\title{
Accuracy of the PM6 and PM7 Methods on Bare and Thiolate-Protected Gold Nanoclusters
}

Joani Mato $¥$ Emilie B. Guidez*‡

‡Chemistry Department, University of Colorado Denver, Denver, CO

*Email: emilie.guidez@,ucdenver.edu

Supporting Information

Table S1: RMSD, HOMO energy, and HOMO-LUMO gap for BP86 and PBE.......... - S2

Figure S1: Molecular orbitals of $\mathrm{Au}_{25}\left(\mathrm{SCH}_{3}\right)^{-}{ }_{18}$ as optimized by PM6.................. S3

Figure S2: Four isomers of Au38(SCH3)24 computed at 3 different levels of theory......... S4 
Table S1 shows a preliminary comparison between the BP86 functional and PBE. As the table shows, BP86 and PBE are in good qualitative agreement with each other. The RMSDs of the bare gold clusters suggest that the geometries of the bare clusters are virtually identical between the two functionals. Some variance arises in the AuSNCs, even though the RMSDs remain relatively small. Similarly, the HOMO energies and HOMO-LUMO gaps are very similar between two methods, differing by at most $0.2 \mathrm{eV}$ in $\mathrm{Au}_{38}\left(\mathrm{SCH}_{3}\right)_{24}$.

Table S1: RMSD, HOMO energy, and HOMO-LUMO gap comparison between BP86 and PBE

\begin{tabular}{l|ccc|cc}
\hline & \multicolumn{3}{c|}{ BP86 } & \multicolumn{2}{c}{ PBE } \\
& RMSD & HOMO/IP & H-L Gap & HOMO/IP & H-L Gap \\
\hline $\mathrm{Au}_{16}$ & 0.02 & -5.731 & 0.603 & -5.548 & 0.612 \\
$\mathrm{Au}_{20}$ & 0.03 & -5.414 & 0.369 & -5.236 & 0.365 \\
$\mathrm{Au}_{25}$ & 0.01 & -2.953 & 0.844 & -2.783 & 0.846 \\
$\mathrm{Au}_{38}$ & 0.01 & -4.921 & 1.149 & -4.693 & 1.140 \\
$\mathrm{Au}_{16}\left(\mathrm{SCH}_{3}\right)_{12}$ & 0.6 & -5.097 & 1.328 & -4.878 & 1.305 \\
$\mathrm{Au}_{20}\left(\mathrm{SCH}_{3}\right)_{16}$ & 0.40 & -5.344 & 1.660 & -5.093 & 1.571 \\
$\mathrm{Au}_{25}\left(\mathrm{SCH}_{3}\right)_{18}(\mathrm{I})$ & 0.06 & -2.757 & 1.258 & -2.650 & 1.253 \\
$\mathrm{Au}_{25}\left(\mathrm{SCH}_{3}\right)_{18}$ & & & 1.223 & -2.627 & 1.180 \\
$(\mathrm{II})$ & 0.14 & -2.750 & & & \\
$\mathrm{Au}_{38}\left(\mathrm{SCH}_{3}\right)_{24}$ & 0.27 & -4.921 & 1.149 & -4.952 & 0.930
\end{tabular}




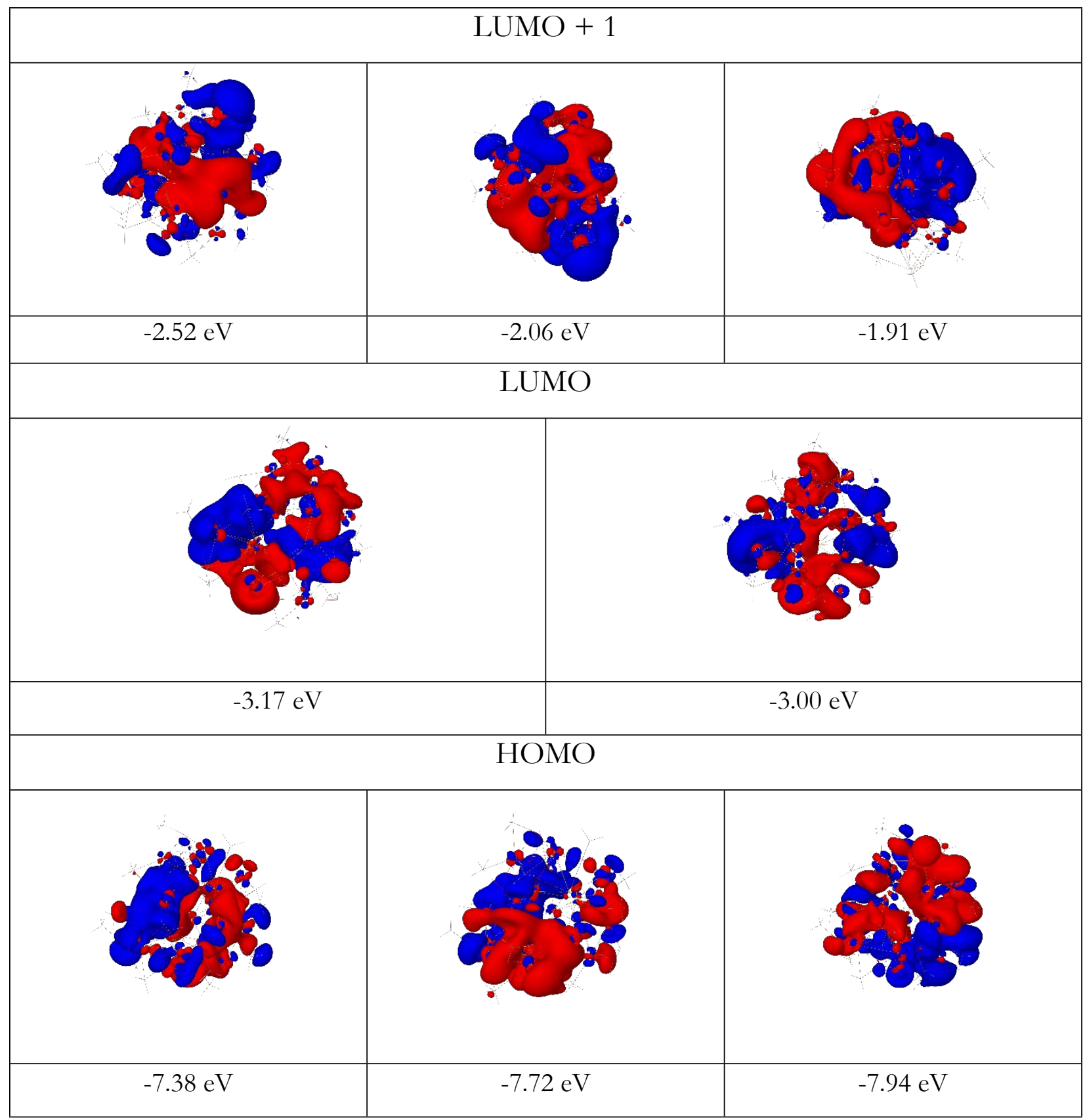

Figure S1: Molecular orbitals of $\mathrm{Au}_{25}\left(\mathrm{SCH}_{3}\right)^{-}{ }_{18}$ as optimized by PM6. 


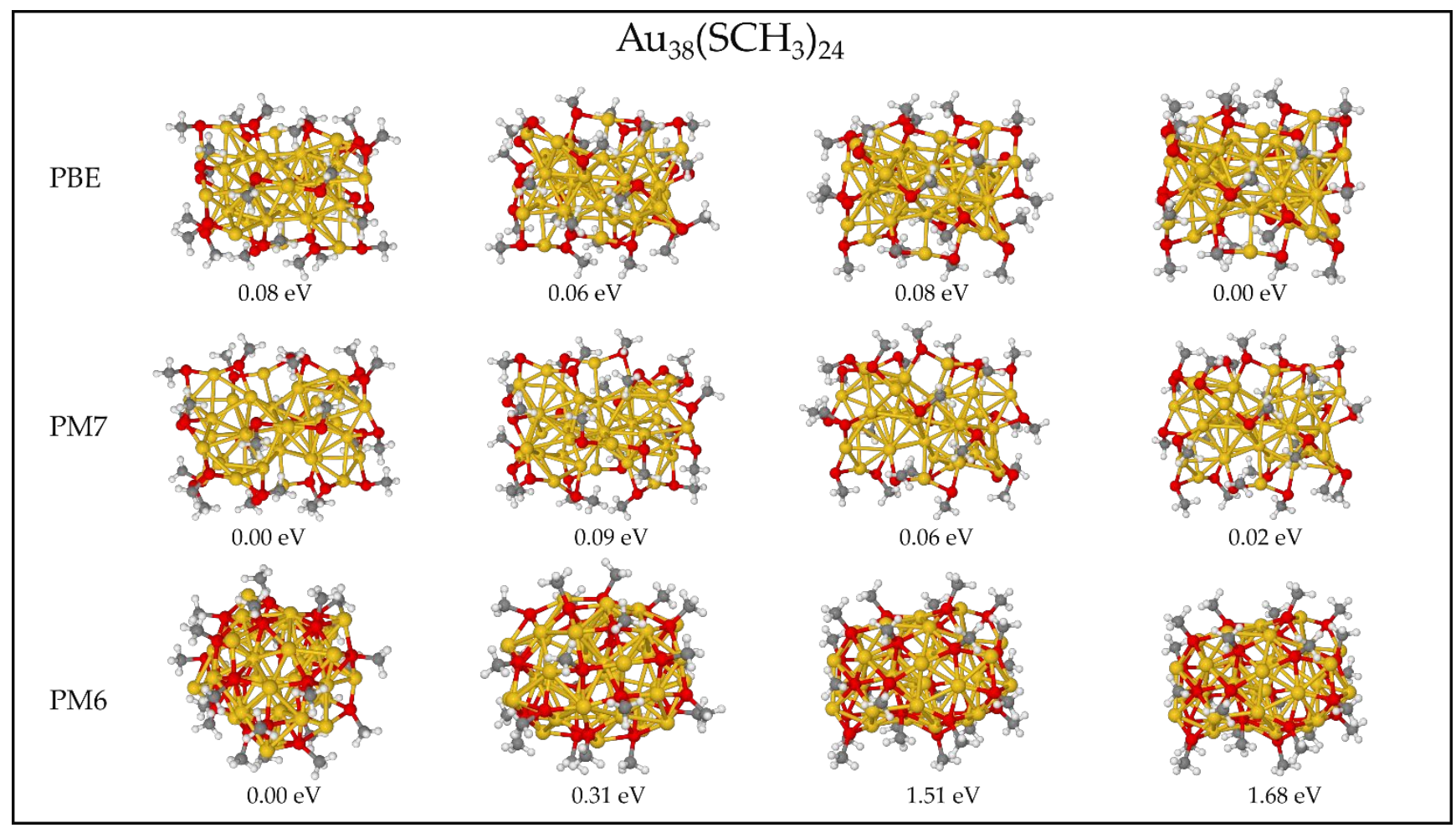

Figure S2: Four isomers of $\mathrm{Au}_{38}\left(\mathrm{SCH}_{3}\right)_{24}$ computed at 3 different levels of theory. 